\title{
Demystifying the Non-human Animal: Analyzing Animal Agency through the Select Narratives of Jim Corbett
}

\author{
Parul Rani ${ }^{1} \&$ Nagendra Kumar ${ }^{2}$ \\ ${ }^{1}$ Research Scholar in English in the Department of Humanities and Social Sciences, Indian \\ Institute of Technology (IIT) Roorkee, Roorkee-247667, Uttarakhand, India. \\ Email Id: parulnet.e@gmail.com, ORCID Id: oooo-ooo2-9934-3585 \\ ${ }^{2}$ Professor of English in the Department of Humanities and Social Sciences, Indian Institute \\ of Technology (IIT) Roorkee, Roorkee-247667, Uttarakhand, India. \\ Email Id:naguk2o@gmail.com
}

\begin{abstract}
The present article revives the jungle knowledge of a renowned Anglo-Indian hunter cum conservationist; Jim Corbett. The contemporary significance of Corbett's first-hand experiences with the animals lies in providing an insight into the ways of the wildlife; unraveling the multilayered relationships of animals with their environment; including humans. The focus on animal behavior takes this paper to exemplify how the interspecies and intraspecies interactions validate the non-human agency. There is an attempt to bring Corbett's select narratives from the collections - Man-Eaters of Kumaon, The Temple Tiger and More Man-Eaters of Kumaon, and Jungle Lore in dialogue with the ethological studies, that complement and precede the debate of the animal agency. Concerned with the question of the animal, this study evolves a critique of Heidegger's dichotomy between the human and animal that sprouts on the idea of the relative non-agent(ic) functionality of the non-human animals. This study opts for an interdisciplinary approach of ethology and philosophy to execute a textual analysis of Corbett's narratives to analyze the animals as agents.
\end{abstract}

Keywords: animals, human-animal relationship, Jim Corbett, non-human animal agency

\section{Introduction}

An overview of the possible continental philosophical trends representing the animal difference presents magnetic dualism if examined minutely. Concerned with the concept of animals as (non)agents, this paper's primary objective is to revisit Heidegger's existential analytic of Da-sein. The literal meaning bestowed on Dasein is "being there" (Large, 2008: 30) in English. However, to avoid the confusion between the being (I) and the things, there is the capitalisation of ' $\mathrm{B}$ ': International License (http://creativecommons.org/licenses/by-nc/4.o/), which permits non-commercial re-use, distribution, and reproduction in any medium, provided the original work is properly cited. For citation use the DOI. For commercial re-use, please contact editor@rupkatha.com. 
denoting the existential Being and "being with a small 'b' to mean something which exists" (Large, 2008: 21). His proposition gets philosophical over science by an ontological inquiry into the meaning of Being. For Heidegger, "Being is always the being of a being" (1996: 7); this Being arises out of that self-awareness whose ability lies in questioning and understanding of the existence of one's being. The being of a being (I/human) goes beyond the being of a thing since it is not the genus that determines Being; instead "being is ontologically and ontically distinctive, namely, Dasein" (Heidegger, 1996: 33). However, the existence of an animal remains a being of a thing as he disapproves genus and species as the constituents of Being: "oute to on genos [Being is not a genus]" (Heidegger, 1996: 2). Thus, the exclusion of animals from the experience of Da-sein gets settled on the basis of their inability (perhaps an unknown ability) to address and find meaning out of their existence.

Heidegger's (1995) writes, "The animal is poor in world, it somehow possesses less. But less of what? Less in respect of what is accessible to it, of whatever as an animal it can deal with ... namely as against the richness of all those relationships that human Dasein has at its disposal (Heidegger, 1995: 193). Also, Heidegger's understanding of the animal being through the lens of Being/human Da-sein constructs poverty in which the animal is not, rather pushed into.

The question of penetrability and its specific manner allows this paper to argue that the variation in the different ways of penetration into the objects stands not in establishing the Being's richness of experience rather in enjoying the varying degree of a method of penetration of two different species. Heidegger exemplifies Bee to show the limited pervasion of an animal, "The worker bee is familiar with the blossoms it frequents, along with their color and scent, but it does not know the stamens of these blossoms as stamens" (1995: 193). However, such instance of the bee's (unlike human) penetrability into its related objects does altogether permit it to see the remains of linguistic perplexity; in which stamens is not understood as stamens by a different species. Conversely, Friend (2004) argues that analyzing a bee's actions and her way of communication are very complicated and not easy to derive a standard meaning: "The most complex system of communication next to that of humans is found in the dance steps of the honeybee" (Friend, 2004: 8).

The animals and their world appear to stand at an unfavorable platform because the fundamental tendency to look at the humans and their world is how they belong to other nonhumans. Also, this implicit understanding, though vague, but is inevitable to comprehend the nature of the meaning of Being through its relation with the beings:

Today-and we can only ever speak of our Dasein as we are doing now-we find ourselves in a favorable situation. It is favorable not merely on account of the great variety and vitality of research but also because of a fundamental tendency to restore autonomy to 'life,' as the specific manner of being pertaining to animal and plant, and to secure this autonomy for it. (Heidegger, 1995: 188)

The stress on our signifies humans an exclusive category finding its existence a favorable stance only by the manner it evolves to relate itself to the animals and the plants. At the same time, human existence forms the world through deriving the meanings out of the things, and its application creates an intellectual environment. However, the non-human animals' inability to recycle their perception of the things deprives them of any creativity, and assigns their world deficient.

The absence of rationality, morality, richness of life, language, consciousness, and reasonable conduct in animals tunes them into the non-agents. Bagemihl is concerned over such 
attributions: "We ascribe meanings and values to their (animals) existence and behaviors in ways that usually have little to do with their biological and social realities, treating them as emblems of nature's purity or bestiality" (qtd. in Szarycz, 2011: 149).

In this regard, the writings of Jim Corbett (1875-1955) stand as masterpieces to establish a relationship between animals and literature. His literary creations (based on his personal experiences with the animals) can be used as a tool to analyze the multidimensional relationships among the components of Nature (including humans), and also find an answer to all the deprivations (language, rationality, morality, etc.) that have been attributed to an animal. Often, the interactions between the species have so richly prevailed that they find meaning with each reading differently. As Herda-Rapp and Marotz say, "The discourse or the words with which we describe wildlife not only articulate the view of the wildlife in question, but also inscribe a set of relationships" (2005: 76). Similarly, though Corbett's narratives fundamentally are based on how the dangerous man-eaters met their end in the Northern part (Kumaon) of the colonial India, but his knowledge of the jungle and a deep insight into the animal behavior potentially render the non-human animals' agency that reacts to the traditional conceptual construction of animal/animality.

To postulate the animals as agents, there is need to brief the animal agency. Špinka and Wemelsfelder write "[a]gency is the intrinsic tendency of animals to behave actively beyond the degree dictated by momentary needs, and to widen their range of competencies (the whole array of cognitive and behavioural experience)" (2011: 28). This definition broadens the boundaries of the animals' capacity beyond the concept of animal automata. It is significant to embrace Leslie's definition as well, he says, "Agency is property of objects rather than property of motion" (1993: 1), making agency intrinsic to a particular object (human/animal) and avoids any narrow understanding of agency that binds its significance to the occurrence of any event. Thus, the intrinsic nature of agency makes its aligned object a performer rather than a passive observer. Similarly, Corbett's texts substantiate the active participation of the animals in their environment at multi-level relationships: interspecies and intraspecies. So the discussion brings the concept of the animals' ability to act competently not being authored(ly) to see them as agents in their way. Specifically, the next section brings the intersectionality of ethological, philosophical, and literary studies to challenge the notion of animal automata. Also, it highlights how the personal interactions with the non-human world can provide a multilayered understanding of humananimal relationships that the later animal behavioral studies validate.

\section{Demystifying the Animal(s):}

\subsection{A Focus on Primates and Birds:}

The development of the sign-language learning in apes flourishes in the second half of the twentieth-century when Allen and Beatrice Gardner, the psychologists, report that their female ape named Washoe is not only able to learn the gestures; instead, Washoe's knowledge extended to "sentence constituents" (qtd. in Seidenberg and Petitto, 1979: 177-178) also. The possibility for the non-human animal to learn and transmit the languages using American Sign Language through the example of Washoe contributes to the dissenting views on the (un)cognitive abilities of the animals. Following the example of Washoe, there are subsequent significant researches in the ape language project in America, as has been detailed by Savage-Rumbaugh et al. (1980); and

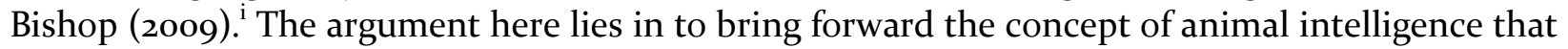
makes them the agents whose roles are lively in their environment. Broadly speaking, the animal 
cognition is taken as defined by Shettleworth, "Cognition, broadly defined, includes all ways in which animals take in information through the senses, process, retain and decide to act on it" (2001: 277). The study of Thomas (1996) makes the different hierarchical levels for examining the cognitive/learning ability of the animals reporting the qualification of the species: squirrel monkeys, rhesus monkeys, and chimpanzees for the level 7 and 8 that comprise concepts of conjunctive, disjunctive, or (bio)conditional relationships. Another popular interspecies relationship of Pepperberg and Alex (grey parrot) strengthens the idea of similarity between the human and bird's brain in the context of learning the vocalization of the words. Pepperberg's study argues on the imitative (not mimicry) capacity of Grey Parrot (Psittacus erithacus) for "the intentional, referential reproduction of a novel English vocalization" (Pepperberg, 2007: 2).

Adequately, the repeated occurrence of the references to the primates' behavior in Corbett's jungle lore substantiates the latter's ability to learn and having the adaptive behaviors. Also, there is an element of sociality that makes them a friend of other species like cheetals; who always prefer to stay near monkeys and langurs. Since the deer(s) and other social animals always get an indication of the danger from predatory big cats, the primates' roles in the jungle become dynamic and follow the strategies of cooperation to sustain in the open environment. Corbett says, "Langurs act differently from red monkeys on seeing a leopard. This may be due to better organization, or to their being less courageous than their red cousins. All the red monkeys in a troupe will chatter and bark at the same time on seeing a leopard" (Corbett, 2015c: 347). Apart from having the interspecies communication, these animals share and follow certain rules like: "[w]hen the leader of the troupe, taking direction from the young one, sees the leopard and takes up the call the young one will stop. Thereafter only the leader and the oldest female will give the alarm call" (Corbett, 2015c: 347), shows the conformity of the group to certain rules. Enacting the codes and conducting them by any species allows the perceiver to see the cognitive faculty in animals. Having the leader in the group exhibits the agreement of the other members to his leadership (however, it also shows the possibility of non-conformity to the group), that states the sense of justice and reliability in non-human animals.

Shifting argument to the Corbett's writings, if the birds are taken into consideration, their capacity to make calls is unquestionable. They show the empathetic capability by signaling the presence of danger in the jungle for their fellow jungle folk. Moreover, the active participation in successfully accomplishing their task of making other social animals aware of the asocial animals is inherently an act of self-awareness. They seem to be the agents whose actions are planned. Corbett says:

All birds and all animals have their own language and though-with few exceptions-one species cannot speak the language of another species, all the jungle folk understand each other's language. The best three of the exceptions are, the racket-tailed drongo, the rufous-backed shrike, and the gold-fronted green bulbul. To bird lovers the racket-tailed drongo is a never ending source of pleasure and interest for, in addition to being the most courageous bird in our jungles, he can imitate to perfection the calls of most birds and of one animal, the cheetal, and he has a great sense of humour. Attaching himself to a flock of ground-feeding birds-jungle-fowl, babblers, or thrushes-he takes up a commanding position on a dead branch and, while regaling the jungle with his own songs and the songs of the other birds, keeps a sharp look for enemies in the way of hawks, cats, snakes, and small boys armed with catapults, and his warning of the approach of danger is never disregarded. (Corbett, 2015c: 253-254) 


\subsection{The Affective Relationship of Corbett with Robin (dog):}

The canine behavioral studies are a step forward to develop the communication between dogs and the humans, also, the cognitive faculties of the dogs. Since dogs are among the most liked pets to have stayed in the human habitat with their caretakers, so it grabs the attention of the researchers to prove the intercommunication between a dog and a human being scientifically, and the former's ability to learn the languages. The project of Kaminski et al. on canine behavioral studies discusses the dog Rico who is not only able to identify the items, instead; efficiently locates the new referent called "fast map" (Kaminski et al., 2004: 1682). His vocabulary gets assimilated with 200 words. Respecting the differences of two species, Bloom responds to the critics of Rico's way of learning by saying, "Rico's limitations might reflect differences in degree, not in kind" (Bloom, 2004: 1605).

Discussion on the canine's cognitive ability undoubtedly leads to examining the relationship between Corbett and his canine through the story "Robin" that is named after the same pet's name. Robin appeals an effusive sentimentality between a spaniel (gun dog) and his caretaker. Robin accompanies Corbett on all his big game hunting grounds who not only appears to indicate Corbett the impending danger but is also capable of tracking the big cat's pug marks in the dense jungle silently. Robin shows his emotions of fear, joy, relaxation, sadness that Corbett understands well. He writes, "The method we (Corbett and Robin) employ is to go out early in the morning, pick up the tracks of a leopard or tiger, and follow them. When the pug marks can be seen, I do the tracking, and when the animal we are after takes to the jungle, Robin does the tracking" (Corbett, 2015a: 33). This writing is indicating the two functions: leave the track and trace the track. Majorly both functions are performed by the non-human animals; leopard and Robin. On the one hand, in Derridean sense, the leopard can be the subject of signifier who is capable of creating a track/mark and simultaneously erasing a track, however, on the other hand, Robin's ability to track the traced marks situates him equipped with the cognitive aptitude. Moreover, it introduces the communication between the species which is taking place through the pug marks, smell, and also through the animal languages. There is a noticeable remark of Robin's competence of tracking after entering the jungle; it makes him directly a non-human agent whose competency is required and also utilized by Corbett in the natural surroundings. Robin is much aware of finding an animal across the winds. Corbett mentions the incident of following a wounded leopard, "Robin knew all that was worth knowing about this method of locating the position of an animal by cutting across the wind, ... he stopped, turned and faced into the wind, and communicated to me that he could smell the leopard (Corbett, 2015a: 39).

Simultaneously, there are also instances of animal empathy; the transmission of the empathetic vibes is between Corbett and Robin. After an encounter with the wounded leopard, Robin seems to feel sorry leaving Corbett alone to face the dangerous situation. Whereas empathy includes the feelings of "sympathy, compassion, caring, helping, grieving, and consoling" (Bekoff and Pierce, 2009: 87), thus Robin is a persona of empathetic animals; "with a large capacity for fellow feeling and behavior that reflects strong social attachments that endure over time" (Bekoff and Pierce, 2009: 87). Corbett explains:

[a] little later, with drooped eyes and drooping ears, he crept silently to my feet ... for the second time in his life, he licked my face-telling me as he did so, with little throaty sounds, how glad he was to find me unhurt, and how terribly ashamed he was of himself for having parted company from me. (2015a: 41) 
Interestingly, the drooped gaze of the animal intersects the interspecies affective friendship, since "gaze and mutual direction of attention (are) as central elements of inter-subjectivity" (Sanders, 2003: 407). The exhibition of ashamedness by Robin, certainly, appears as a response to his act of leaving Corbett alone in a dangerous situation. Also, the response of Robin challenges to that philosophical notion which deprived animal "of response" (Derrida, 2008: 32).

For Derrida, the psychoanalysts' distinction between the response and the reaction is problematic. Since the "logic of the unconscious is founded in on a logic of repetition . . . will always inscribe a destiny of iterability," hence, there is the possibility of "some automaticity of the reaction in every response" (Derrida, 2008: 125). To make an address to the cybernetic program when Derrida offers to include that "it must conserve the notion of writing, trace, grammé [written mark], or grapheme, until its own historico-metaphysical character is also exposed" (Derrida, 1997: 9), he includes the grammé/mark as the important unit of language. If the mark is the unit of language, then the animal's capability of producing the mark or trace becomes significant in the discourse of Lacan and Derrida as well. Because a trace is produced after its inscription by an animal, so it indicates the presence of the animal in his absence to the tracking hunter.

However, for Derrida, the notion of trace is also problematic because he substitutes "the concept of trace for that of signifier" (2008: 135). The capability to trace itself shows the potentiality of erasing a trace. Also, every conscious effort to erase a trace, at the same time, inscribes another trace. He condemns that psychoanalyst/philosophical trend that has given the right to the human to attribute all the features that it deprives the animal of; pretense of pretense, covering the tracks, etc. Moreover, the humans cannot have the power of erasure of a trace; instead, it is inherent in the trace to be erased. Addressing the psychoanalysts, Derrida writes:

Is it necessary to recall that every erased trace, in consciousness, can leave a trace of its erasure whose symptom (individual or social, historical, political, etc.) will always be capable of ensuring its return? . . . It is inherent to a trace that it is always being erased and always capable of being erased ... In this regard the human no more has the power to cover its tracks than does the so-called 'animal.' (2008: 136)

\subsection{The Language of Jungle Folk:}

The notion of the animals' language as a mode of communication is pertinent to Corbett's texts where he analyzes the behavior of the animals. The motto of the changing animal behavior is to ascertain the balance in Nature. Each animal folk has its own role to play in the jungle. Corbett talks about the animals' languages at great length without any hesitation of acknowledging the animals and birds with the faculty of language/communication. He writes about his early days in the jungle, "I had yet to learn the habits of the animals, their language, and the part they played in the scheme of nature ... I was also absorbing the language of the birds and understanding their function in nature's garden" (Corbett, 2015c: 252). The different species play different roles significantly as few of them are assigned to beautify the natural surroundings; others are to maintain the balance. The categorization of Corbett of these creatures in certain groups is inevitable to understand the birds and animals' agency:

(a) Birds that beautified nature's garden: minivets, orioles, and sunbirds. (b) Birds that filled the garden with melody: thrushes, robins, and shamas. (c) Birds that regenerated the garden: barbets, hornbills, and bulbuls. (d) Birds that warned if danger: drogos, red junglefowl, and babblers. (e) Birds that maintained the balance in nature: eagle, hawks, and 
owls. (e) Birds that performed the duty of scavengers: vultures, kites and crows...(g) Animals that beautified nature's garden: deer, antelope, and monkeys. (h) Animals that helped to regenerate the garden by opening up and aerating the soil: bears, pigs and porcupines. (i) Animals that warned of danger: deer, monkeys and squirrels. (j) Animals that maintained the balance in nature: tigers, leopards, and wild dogs. (Corbett, 2015c: 252-253)

To develop an understanding of the natural world and to see the animals as agents, there is a core value to understand the ways of interaction between the species. Simultaneously, it is interesting to note that by knowing the animals' communication, it is possible for Corbett to access the big cats for the hunt. So the roles of certain animals are not confined to their species rather it become meaningful for those who got to comprehend their signals. For instance, Corbett mentions the changing nature of the alarm calls in the context to whether the immediate action is required, "It is the sound that is only heard once, like the snapping of a twig, a low growl, or the single warning call of bird or of animal, that is difficult to locate, is of immediate danger, and calls for instant action" (Corbett, 2015c: 266). Mukherjee considers that the understanding of an ecosystem is liable to both human and nonhuman, 'environment' as an integrated network of human and non-human agents acting historically" (2010: 5). In the course of narrating the maneater big cats, Corbett comes very close to authenticate the animal agency through their behavior. Monkeys and the langurs (leaf monkey) are the crucial informants to their fellow animals like sambhar (sambar deer), deer, kakar (Indian muntjac) and others, of the presence of the big cats because of their predating nature. Steward's statement, "Animals do such things as build nests and burrows, seek food, attempt to elude predators. The more sophisticated among them appear to communicate with one another, even play. They fight. They groom" (Steward, 2009: 217), reinforces the noticeable reactions of the animals towards Tall Des tigress, "The jungle appeared to be well stocked with game, and I repeatedly heard sambhar, kakar, and langur giving their alarm calls, and more than once I heard pheasants, jays, and white-capped laughing thrush mobbing the tigress" (Corbett, 2015b: 157).

Other than the inevitability of communication among the animals, the tigers insinuate to jest Corbett in the serious sport of man-eating hunting. Being habituated to stalk and hunt the tigers on foot, Corbett rejoices more chances to observe the animals in their natural surroundings and sometimes to credit the physical and mental vitality to these animals. There is an immense sense of awareness in Chuka man-eater:

It would not have been possible for a human being to have got over that steep and difficult ground without using his hands and without making considerable noise, but the tiger accomplished the feat without making a sound the nearer he came to the flat ground the more cautious he became and the closer he kept his belly to the ground. When he was near the top of the bank he very slowly raised his head, took a long look at the tree the men had climbed, and satisfied that it was not tenanted sprang up on to the flat ground and passed out of sight under me. (Corbett, 2015b: 111)

The incredible strength and the reasoning of the tiger reconfigure the notion of reasoning as the sole propriety of humans. In fact, the act of slinking is a performative feat of the Chuka man-eater that solicits the conscious awareness in the animal. Also, such course of awareness has a decisive role in shaping the actions, "Conscious awareness entails the actor indicating 'things' to his or her self, devising an understanding of the objects so indicated, and using this understanding to shape lines of action" (qtd. in Sanders, 2007: 324-325). Along the same lines, the narratives imply the Tigers' consciousness in stalking the jungles, attacking the predators, soothing their wounds, 
caring for their mates, teaching and loving their cubs, hiding their foods and above all the sense of humor which they possess and at times show towards Corbett. The temple tiger plays many times with Corbett and evades his bullet, "I saw the tiger ... When he saw me looking down on him he flattened his ears ... I could imagine him saying to himself, 'Well, you have now seen me, and what are you going to do about it?"' (Corbett, 2015b: 32) so he realizes the fun the tiger had made on him, "I know that crows and monkeys have a sense of humour, but until that day I did not know that tigers also possessed this sense" (Corbett, 2015b: 38).

\subsection{The Affective Faculty in Animals:}

The discussion on the animal agency implants the similarities between the human and nonhuman subjectivities. Gompertz tries to minimize the gap between the two by assigning a common share of emotions by men and animal, "Things which affect us, generally seem to affect them in the same way: and at least the following sensations and passions are common to both, viz. hunger, desire, emulation, love of liberty, playfulness, fear, shame, anger, and many other affections" (qtd. in Mayer, 2009: 185). Similarly, Corbett says, "Fear stimulates the senses of animals, keeps them 'on their toes', and adds zest to the joy of life; fear can do the same for human beings" (Corbett, 2015c: 288). Likely, the emotions of love and affection of the Chuka tigress for her cubs draw irresistible attention which shows the animal world is full of the unique passion of the motherhood including the transmission of instructions, teaching, facing the danger for her cubs, etc. when she leads them to take the food:

The behaviour of the cubs was as interesting as their mother's. Step by step they followed in her tracks; never trying to pass each other ... The ground was carpeted with big sal leaves as dry as tinder over which it was impossible to move silently; however, every pad was put down carefully and as carefully lifted, and as little sound as possible was made ... Her lying down was apparently intended as a signal to the cubs to go forward in the direction in which her nose was pointing . . By what means the mother conveyed the information to her cubs that there was food for them at this spot I do not know, but that she had conveyed this information to them there was no question. (Corbett, 2015b: 105106)

On the other way, Tall Des tigress challenges and faces Corbett intermittently and escapes too. She becomes more dangerous after losing her cubs by Corbett's bullet, "A tiger that has made up its mind to avenge an injury is the most terrifying animal to be met with in an Indian jungle" (Corbett, 2015b: 177). She seems to be more aware in the game of killing with a human being and advances to the safe positions to protect her and having a revert attack on the hunter, "As soon as she becomes aware that I was following her and she considered that I was within her reach, she would launch an all-out attack on me" (Corbett, 2015b: 177). Even though she got badly wounded by Corbett's assaults but is capable of showing her prudence, he is impressed with: "Walking downhill with an injured leg is far more painful than walking uphill and as soon as the tigress recovered from her dazed condition she would stop going downhill and would make for cover in which to nurse her injury" (Corbett, 2015b: 149). Another noticeable example of an amazing sense of motherhood caring is of the red monkeys when the alarm call is deliberately made to protect their young ones. Corbett writes, "The warning given by the red monkeys has been heeded, and all the mothers in the troupe have got hold of their young ones, and all eyes are turned in the direction from which the warning came" (Corbett, 2015c: 347). To care for their off springs, to launch an attack in order to survive, to have hunger, anger, shame, etc. as discussed above draw the human and animal on the same platform of 'natural laws' as discussed in Pañcatantra's 
(India's ancient animal fables collection). Rukmani says, "Humans and other share the world equally in the Pancatantra, and they are all governed by the same natural laws" (qtd. in Kemmerer, 2006: 107).

The difference between response and reaction and the animals' ability to respond to inter/intra-species are the fundamental to deconstruct the animal existence. The above arguments, on the one hand, help to dismantle the lens that saw animals as mere mechanical objects, and on the other hand, they postulate the animal agency which makes them the aware agents in (of) their environments. Their actions can be understood as a result of an aware state of mind, not merely an accidental happening. This is an extended view of Darwin's thoughts when he considers animals the actors, "Simple ideas-like a bird weaving for pleasure or singing for its own amusement-embody assumptions and consequences that are far from simple, namely, that animals' actions are experientially meaningful and actively authored" (qtd. in McFarland and Hediger, 2009: 2-3). Similarly there are several instances of the authorship of the animals' actions to remind here from Corbett's text: first, when the alarm call is given by the leader of a langur group followed by a female's call 'tch' (like the sound of a sneeze) indicates the young ones to be unafraid from the leopard's presence because "if he had been hungry and out to kill he would not have walked out on to the open watercourse as he has done" (2015c: 348). Secondly, it is worth mentioning to see the big cats' method of carrying their kills by prudently avoiding any trace for the other animals to follow. "[t]igers and leopards when crossing a road with a kill lift the kill clear of the ground, and this I believe they do to avoid leaving a scent trail for bears, hyaenas, and jackals to follow" (Corbett, 2015c: 277). Since these carnivores are asocial animals, so their cognitive abilities to some extent can be mapped in stark contrast to the social animals. They show prudence in silent tracking of their prey and then hiding their kills. Borregoa writes, "[c]ognition in leopards and tigers evolved in the absence of social complexity" (Borregoa, 2017: 262). They are seen seldom in an association, "leopards, tigers, and jaguars are asocial and associate only during mating and with dependent offspring" (qtd. in Borregoa, 2017: 262).

\subsection{Sociality in Animals:}

McFarland and Hediger's definition of animal agency include "free will, ability, rationality, mind, morality, subjectivity" (2009: 3). Although these terms seem to overlap each other and signify the existence of one over the other (as discussed above the animals' ability to communicate their message to human and beyond the human species), the question of morality in animals is very pertinent to address here. Since the question of morality in animals is a very uninvited and unconvincing phenomenon in the philosophical trend, there are the issues of defining the morality in animals, however, at the same time the categorization of the social and asocial animals through their behaviour can be a shred of authentic evidence to find out the question of morality in the non-human animals. Sapontzis writes, "The reason why animals cannot act morally, if they cannot, is not to be found at the behavioral level" (Sapontzis, 1987: 31). Breaking the traditional Western thinkers' notion of the interlinking between rationality and morality, David Hume is amongst the ones who introduces emotions the basis of morality, and that be common in both: the humans and the animals. He says, "[t]he three relations of resemblance, contiguity and causation operate in the same manner upon beasts as upon human creature" (Hume, 2007: 213), and further, pays attention to the union of emotions among the animals and humans, notably, calling the animals as inferior species. "[t]here is an union of certain affections with each other in the inferior species of creatures as well as in the superior, and that their minds are frequently convey'd thro' a series of connected emotions" (Hume, 2007: 213). But the 
deprivation of virtue or vice in the animals keeps them beyond any moral judgment. However, Sapontzis reacts to the un-virtuous state of the animals and says, "[m]any animals possess sufficient sensitivity and intelligence to recognize virtues and to do virtuous deeds, they seem to lack the ability to lead a fully moral life dedicated to the attainment of an ideal" (1987:44).

When there is a discussion on the morality in animals, the primatologist, Frans de Waal's (2006) study is inseparable from this idea. Although primarily his work is concerned with the evolution of human morality, the entanglement of human and animal morality makes his study a remarkable contribution to understanding the morality in animals. Objecting to the Veneer Theory (considering humans bestial by nature), in the contention of Huxley's remarks Waal makes an indicative expression: "Humans are, he suggests, by nature good" and this goodness is inherited from "our nonhuman ancestors" (qtd. in Ober and Macedo, 2006: xii). However, he indicates the variation of the degree of the human goodness and the nonhuman goodness, but the nonhuman morality is "the foundation of more complex human morality" (qtd. in Ober and Macedo, 2006: xii). In opposition to the Western philosophy's claims of rationality as an active agent in making the possible functioning of moral behavior, Waal considers sociality and emotions the root cause of morality. It is not a unique phenomenon or a cultural innovation that is achieved only by the humans rather it results from an evolution that is social in its nature: "[m]orality is neither unique to us nor a conscious decision taken at a specific point in time: it is the product of social evolution" (Waal, 2006: 6). Also, this sociality is common to the human and non-human spheres. He considers monkeys and apes are the "highly social ancestors," and states that "sociality has become ever more deeply ingrained in primate biology and psychology" (Waal, 2006: 4). The positioning of morality has more direct and clear affiliations with the emotional core of the human and non-human nature, and that is evidenced in the social animals who live in groups and always involve communicating the presence of food, danger, and the other resources for their lives.

Going beyond the emotional faculty in primates, ethologist Niko Tinbergen and biologist George Schaller suggest "we might learn a lot about the evolution of human social behavior by studying social carnivores, species whose social behavior and organization resemble that of early hominids in a number of ways (division of labor, food sharing, care of young, and intersexual and intrasexual dominance hierarchies)" (qtd. in Bekoff and Pierce, 2009: 9). Likely, the sociality in animals is a noteworthy constituent of Corbett's elaboration of the jungle lore. Other than the primates, there are the other species that seem to be social enough to help and care for their group. The animals adopt different vocalizations for communicating the specific state of affairs with their peers. The examples of cheetal (spotted deer) as analyzed by Corbett strongly convey the ways of the jungle folk to help each-other from the predators. He writes:

[a] herd of cheetal in an open glade ... One of the young ones that had been sleeping in the sun got to its feet, stretched itself, and kicking up its heels raced across the glade towards a fallen tree; this was a signal to the other young ones that a game of 'follow the leader' was on ... the leader carried on into the jungle ... A hind that had been lying down now got to her feet, looked in the direction in which the young ones had gone, and gave a sharp bark. (Corbett, 2015c: 264-265)

Following the rules of the group shows that there are specific codes to be followed which further exhibit the animal agency. Also, the sharp bark given by the young one against the presence of a woodcutter is meant only for the young ones. Bark to the whole herd indicates the man's presence within hundred yards range. Thus, the various adaptive behaviors of animals get accredited with the social and moral elements in their respective groups. Morality in animals is 
closely aligned to the genre of social living in animals: "Morality is a broadly adaptive strategy for social living that has evolved in many animal societies other than our own ... they (animals) have a complex and nuanced repertoire of emotions as well as a high degree of intelligence and behavioral flexibility" (Bekoff and Pierce, 2009:3). The morality in animals is not confined to their species instead there are instances of interspecies morality where the non-human animals' empathy can be traced for the human beings as well. ${ }^{\text {ii }}$

However, there is a variation between the call of a mother for young one and the call of a hind warning his fellow mates against a human being: "[c]alling for different reasons was not to be found in the call itself, but in the intonation of the call" (Corbett, 2015c: 265). Also, the nature of the signal also indicates the possibility of the instant action taken in the situation of danger. In Corbett's views, the alarm calls by the langurs, cheetals, or by the peafowl is easy to understand, but the discretion of the call determines the actions of the animals. In many instances, the language of cheetal proves to be very crucial for Corbett to locate the predatory animals. It is not only the enabled treetop birds/animals, instead; other animals like kakar, sambhar, and cheetal also make the jungle folk aware of the predators. Against the predominant notion, Corbett considers kakar as one of the most reliable informants. Although his physique seems defenseless, he is a courageous animal who dares to stay with a tiger in a dense forest. The story of Robin mentions the role of the deer(s) in making Corbett aware that the wounded leopard is in his vicinity. The story adds, "From the manner in which the chital were calling it was evident that the leopard was in full view of them . . . the leopard was alive and had moved . . the position of the leopard ... we could get by stalking the chital" (Corbett, 2015a: 35).

\section{Conclusion:}

The study presents a compact view of animal agency and through the examples of changing animal behavior in different situations reacts to the thesis of animal poverty in the world. Simultaneously, it shows that the inclusion of animals as beings in order to have the experience of Da-sein delineates the unjustified presence of the animals in philosophy. The discourse on the animals is closely entangled with ascertaining what the humans are. However, such discourses make the animals insignificantly significant. Also, this significance lies in studying the animals' world from a species' point of view, certainly not to be understood in comparison with the human species. The study finds the actions of animals are deliberate that indicates the different levels of rational process on the animal mind.

Although the natural sciences' periphery is well developed in this area, such issues are certainly needed to be addressed through the literary creations as well to enrich the comprehensibility of literature and its areas of studies. The relevance of Corbett's writings in the present scenario lies in immortalizing the relationship of the animals with the text. Also, the revival of jungle narratives unfolds the value of personal encounters with non-human animals that are abundant in conveying the concept of animal agency. Also, it presents a counter-narrative to that second-hand knowledge which is conveyed in philosophy with the centeredness of humans. The study also finds the various levels of possible interspecies and intraspecies communication that goes beyond the linguistic limitations of language as such. The befitting of the Corbett's text with the ethological and philosophical contexts shows the concerning dialogue between literature and science whose approaches vary but the central argument (the question of animal) remains the same. At any point in time, this study does not negate the degree of differences between the human animal and non-human animal, instead; it ventures to admirably 
acknowledge the similarities and differences: animals and humans are imbibed with. This assertion resonates with Haraway's clear understanding of the animal rights movement: "Movements of animal rights are not irrational denials of human uniqueness; they are clearsighted recognition of connection across the discredited breach of nature and culture" (Haraway, 1991: 152).

\section{Notes}

i See Bishop (2009) "Forms of Life" (pp. 220-221) for the details of various projects intended to teach the languages to chimpanzees. The projects include: of David Prameck's in 1970s; LANA by Duane Rumbaugh in 1972; Patterson's in 1976; and Terrace and Miles' respective efforts for Nim and orangutan Chantek.

Also, see, Savage-Rumbaugh et al. (1980) for an insightful analysis of the use of language by Apes.

ii See Bekoff and Pierce (2009: 108-109) for the examples of interspecies morality where the animals proved to be extraordinarily protective for the human beings.

\section{References}

Bekoff, M. \& Pierce, J. (2009). Wild Justice: The Moral Lives of Animals. Chicago: The University of Chicago Press.

Birke, L. (2002). Intimate Familiarities? Feminism and Human-Animal Studies. Society and Animals 10 (4): 429-436.

Bishop, R. (2009). Forms of Life: The Search for the Simian Self in Ape Language Experiments. In Sarah E. McFarland and Ryan Hediger (Eds.), Animal and Agency: An Interdisciplinary Exploration (pp. 207228). Leiden: Brill.

Bloom, P. (2004). Can a Dog Learn a Word. Science, 304 (5677), 1605-1606. DOI: 10.1126/science.1099899

Borregoa, N. (2017). Big cats as a model system for the study of the evolution of intelligence. Behavioural Processes, 141, 261-266. DOI: 10.1016/j.beproc.2017.03.010

Corbett, J. (2015a) [1944]. Man-Eaters of Kumaon. 24 ${ }^{\text {th }}$ impression. New Delhi: OxfordUniversity Press.

Corbett, J. (2015b) [1954]. The Temple Tiger and More Man-Eaters of Kumaon. $39^{\text {th }}$ impression. New Delhi: Oxford University Press.

Corbett, J. (2015c) [1991]. The Second Jim Corbett Omnibus: My India, Jungle Lore, Tree Top. $33^{\text {rd }}$ impression. New Delhi: Oxford University Press.

Derrida, J. (1997). Of Grammatology. Gayatri Chakravorty Spivak (trans.). Corrected Edition. Baltimore: The Johns Hopkins University Press.

Derrida, J. (2008). The Animal That Therefore I Am. Marie-Louise Mallet (Ed.). David Wills (trans.). New York: Fordham University Press.

Friend, T. (2004). Animal Talk: Breaking the Codes of Animal Language. New York: Free Press.

Haraway, D. J. (1991). Simians, Cyborgs, and Women: The Reinvention of Nature. New York: Routledge. 
Heidegger, M. (1995). The Fundamental Concepts of Metaphysics: World, Finitude, Solitude. William McNeill \& Nicholas Walker (trans.). Bloomington: Indiana University Press.

Heidegger, M. (1996). Being and Time: A Translation of Sein und Zeit. Joan Stambaugh (trans.). Albany: State University of New York Press.

Herda-Rapp, A. and Marotz, K. G. (2005). Contested Meanings: The Social Construction of the Mourning Dove in Wisconsin. In Ann Herda-Rapp and Theresa L Goedeke (Eds.), Mad about Wildlife: Looking at social conflict over wildlife (pp. 73-98). Leiden: Brill.

Hume, D. (2007). A Treatise of Human Nature: A Critical Edition (vol. 1). David Norton \& Mary J Norton (Eds.). New York: Oxford University Press Inc.

Kaminski, J. et al. (2004). Word Learning in a Domestic Dog: Evidence for "Fast Mapping”. Science, 304 (5677), 1682-1683. DOI: 10.1126/science.1097859.

Kemmerer, L. (2006). In Search of Consistency: Ethics and Animals. Leiden: Brill.

McFarland, S. E. \& Hediger, R. (2009). Approaching the Agency of Other Animals: An Introduction. In McFarland and Hediger (Eds.), Animals and Agency: An Interdisciplinary Exploration (pp. 1-20). Leiden: Brill.

Large, W. (2008). Heidegger's Being and Time: An Edinburgh Philosophical Guide. Edinburgh: Edinburgh University Press.

Leslie, A. M. (1993). A Theory of Agency. Retrieved 19 March, 2019, from $<$ http://ruccs.rutgers.edu/images/tech rpt/tr-12/agency12.pdf $>$.

Mayer, J. (2009). Representing the Experimental Animal: Competing Voices in Victorian Culture. In Sarah E. McFarland \& Ryan Hediger (Eds.), Animals and Agency: An

Interdisciplinary Exploration (pp. 183-205). Leiden: Brill.

Mukherjee, U. P. (2010). Postcolonial Environments: Nature, Culture and the Contemporary Indian Novel in English. London and New York: Palgrave Macmillan.

Macedo, S. \& Josiah, O.(Eds.). (2006). Introduction. In Frans de Waal, Primates and Philosophers: How Morality Evolved (pp. ix-xix). Princeton: Princeton University Press.

Pepperberg, I. M. (2007). Grey parrots do not always 'parrot': the roles of imitation and phonological awareness in the creation of new labels from existing vocalizations. Language Sciences, 29, 1-13. DOI:10.1016/j.langsci.2005.12.002

Sanders, C. R. (2007). Mind, Self, and Human-Animal Joint Action. Sociological Focus, 40 (3), -336. DOI: 10.1080/00380237.2007.10571313

Sapontzis, S. F. (1987). Morals, reason, and animals. Philadelphia: Temple University Press.

Savage-Rumbaugh, S. E. et al. (1980). Do Apes Use Language? One research group considers the evidence for representational ability in apes. American Scientist, 68 (1), 49-61.

Seidenberg, M. S. \& Laura, A. P. (1979). Signing behavior in apes: A critical review. Cognition, 1, 177 - 215.

Shettleworth, S. J. (2001). Animal cognition and animal behaviour. Animal Behaviour, 61, 277-286. DOI:10.1006/anbe.2000.1606

Špinka, M. \& Wemelsfelder, F. (2011). Environmental Challenge and Animal Agency. In Michael C Appleby, et al. (Eds.), Animal Welfare (pp. 27-43). Second Edition. Oxfordshire and Cambridge: CAB International.

Steward, H. (2009). Animal Agency. Inquiry, 52 (3), 217-231. DOI: 10.1080/00201740902917119 
14 | Rupkatha Journal, Vol. 11, No. 3, 2019

Szarycz, G. S. (2011). The Representation of Animal Actors: Theorizing Performance and Performativity in the Animal Kingdom. In Nik Taylor \& Tania Signal (Eds.), Theorizing Animals: Rethinking Humanimal Relations (pp. 149-174). Leiden: Brill.

Thomas, R. K. (1996). Investigating Cognitive Abilities in Animals: Unrealized Potential. Cognitive Brain Research, 3, 157-166.

Waal, F. d. (2006). Primates and Philosophers: How Morality Evolved. Stephen Macedo and Josiah Ober (Eds.). Princeton: Princeton University Press. 